\title{
Choice of design solutions for BREEAM international certificate
}

\author{
Katarzyna Ćwik ${ }^{1}$, Paweł Nowak ${ }^{1 *}$ \\ ${ }^{1}$ Warsaw University of Technology, Civil Engineering Faculty, Armii Ludowej 16, 00-637 Warsaw, \\ Poland
}

\begin{abstract}
The aim of this paper is to describe and explain the influence of BREEAM International system on the choice of design solutions. Authors present the algorithm for implementation during the process of applying for BREEAM certificate. The algorithm was prepared to create a clear scheme that would enable any party of the investment process, especially designers, to understand and effectively go through all the fundamental stages of assessing the performance of the building and to become successfully certified.
\end{abstract}

\section{Introduction}

BREEAM (Building Research Establishment's Environmental Assessment Method) is the world's most popular, multi-criteria environmental assessment method for buildings. At the moment (end of year 2016), 554733 buildings are certified and 2256752 are registered in this system in 78 countries [1]. First standard concerning assessment of commercial buildings in Europe was launched in 2008 by BRE. Then, in 2009 and 2010 the schemes were updated. It was decided to launch a new improvement of BREEAM International in 2011, expanding the scope of the certification to residential buildings and buildings outside of Europe. The main aim of BREEAM certification is to measure and describe the environmental performance of the building during the Design Stage (DS) and PostConstruction Stage (PCS). The system aims mainly at reducing the impact of buildings on the environment and broadening the concept of sustainable buildings. The aforementioned is applied by ensuring that best environmental practice is implemented during the Design Stage and Post-Construction Stage of the building by setting the criteria and standards to be followed [5, 6, 7, 9] - all concerning lowering the environmental impact of the building. BREEAM enables to raise the public awareness and allows for demonstrating progress towards environmental objectives. All is performed according to BRE Global's guides, publications, standards and certification schemes.

There are two stages distinguished as mentioned before - Design Stage and PostConstruction Stage. The Design Stage (DS) assessment is the intermediate measurement of building's performance, mostly completed at the stage of design that allows for checking and reporting the accordance to the technical guidance. This stage leads to the interim BREEAM Certificate. The Post-Construction Stage leads to final BREEAM certificate and

*Corresponding author: p.nowak@il.pw.edu.pl 
represents the final performance of the building. It is completed and certified when all building works are completed. Here two approaches can be distinguished: post-construction review confirming the rating achieved at the design stage or the full review in case the interim assessment has not been carried out.

The crucial definitions need to be enclosed in order to perform the further analysis of influence of BREEAM on the choice of design solutions $[2,9,10]$ :

- Shell and Core - Typically Shell and Core building covers base building elements such as structure, envelope and fit out of common areas. A core HVAC system may be provided to allow for tenant connections

- Green Building Guide - a formal document that provides detailed advice to the proposed/actual tenant(s) of the building on how to minimize the environmental impacts of the building. The guide will have a particular focus on those impacts that can be influenced by the tenant(s) as a result of their building fit out.

BREEAM rating is carried out by the assessor - licensed and monitored specialist in BREEAM issues. The specialist must determine the rating using Assessor's Spreadsheet Tool and associated calculators. Firstly, according to the detailed assessment criteria presented in the manual, a number of credits awarded is determined in ten categories. Then, the percentage of credits achieved is calculated for each category and it is multiplied by corresponding weighting (listed in the table 1), to give the section score.

Table 1. BREEAM sections weighting, source: [2]

\begin{tabular}{|c|c|}
\hline \multirow[b]{2}{*}{ BREEAM section } & Weighting [\%] \\
\hline & $\begin{array}{l}\text { New buildings, extensions } \\
\text { and major refurbishments }\end{array}$ \\
\hline Management & 12 \\
\hline Health \& Wellbeing & 15 \\
\hline Energy & 19 \\
\hline Transport & 8 \\
\hline Water & 6 \\
\hline Materials & 12,5 \\
\hline Waste & 7,5 \\
\hline Land Use \& Ecology & 10 \\
\hline Pollution & 10 \\
\hline Innovation & 10 \\
\hline
\end{tabular}

Finally, provided that all minimum standards have been met, calculated scores are added together to give the overall BREEAM score. Comparing to the table below, the BREEAM rating is achieved. Rates are: Unclassified $<30$; Pass $\geq 30$; Good $\geq 45$; Very Good $\geq 55$; Excellent $\geq 70$; Outstanding $\geq 85$. There is also an additional (up to $10 \%$ ) score for Innovation, available to projects that demonstrate that they have gone above and beyond the best practice levels of BREEAM. 


\section{Algorithm Proposal for Office Building BREEAM Assessment}

Authors present the algorithm for implementation during the design process when it is foreseen to apply for the BREEAM certificate. The aim of this algorithm is to show the scheme that would enable any party of the investment process to effectively go through all the fundamental stages and become successfully certified. The certification process begins with choosing an appropriate BREEAM scheme. This and all the following steps should be guided by a competent person- licensed assessor. To become an assessor, one should had been trained and examined by BRE Global before. Typically, the knowledge of a person is assessed via undertaking a multiple choice examinations. Once the tests are passed, the assessor can apply for a license and is able to carry out the projects as a professional.

Firstly, the assessor carries out a pre-assessment, which helps to predict a likely score by using a Pre-Assessment Estimator [10]. Once this part is finished, the assessor registers the project for the assessment - and it is done only once. BRE Global evaluates and makes certification decision only on registered assessments. The project can be assessed both at the Design Stage and Post-Construction Stage. The first part of the algorithm is presented on Fig. 1.

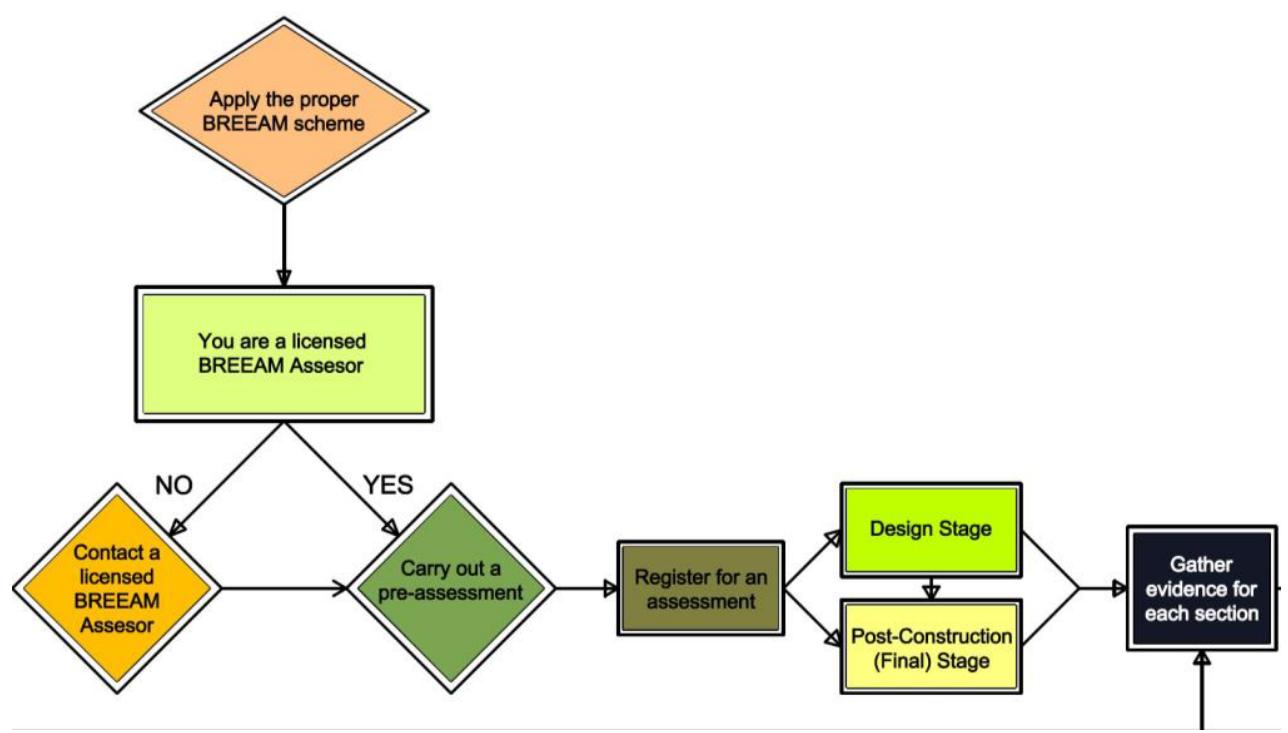

Fig. 1. Initial part of the BREEAM assessment algorithm [own source]

The next step is to collect all the evidence for each of ten sections in order to demonstrate the degree of compliance of a client's project with the performance criteria defined in the technical manual. The aforementioned is done by assessor. The client's responsibility lies in ensuring that all the relevant parties (consultants, designers, contractors, building owners, etc.) will supply the information needed to the assessor at the appropriate time. Once all the evidence is gathered, the Internal Quality Assurance takes place. At this stage, all the documents are checked by the appointed person before they are issued to the assessor.

The assessor is responsible for maintaining a record of this information and ensuring that it is correctly interpreted against the assessment criteria. That is why close cooperation of assessors, their clients and the project team is strongly advised. If the evidence is missing 
or not clearly prepared, BRE Global will not be able to make a positive certification decision.

As a consequence, the certification process may be delayed. The elements to be considered during the design process in terms of BREEAM certification should be as follows [3, 4]: management and maintenance (starting with Commissioning, taking under consideration Life Cycle Cost Analysis), Health and Wellbeing, Energy use, Internal transport and routes, Water use and management, Materials, Waste management, Land use and Ecology, Pollutions, Innovative aspects of the building.

Figures 2 and 3 shows the most important steps of the algorithm (examples) - gathering and assessment of the data.
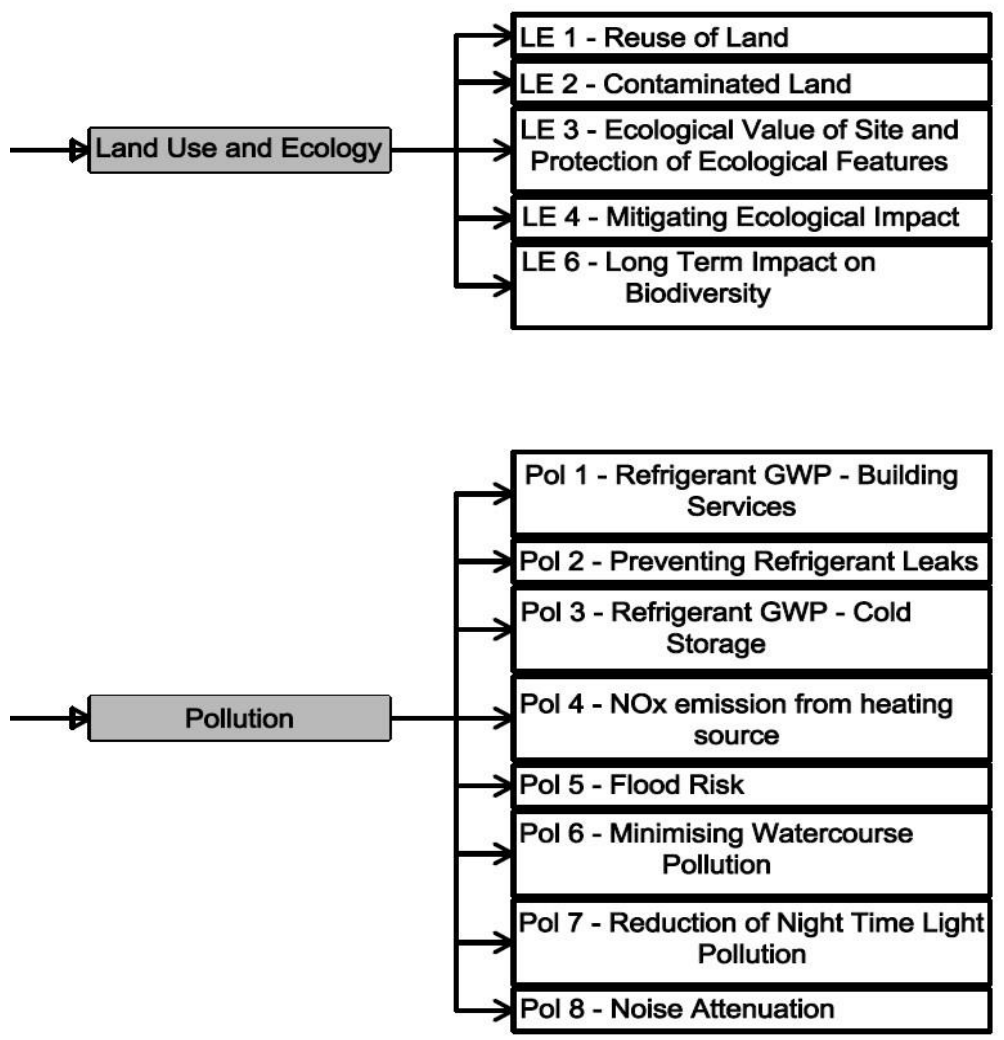

Fig. 2. Crucial part of the BREEAM assessment algorithm Land Use and Ecology elements example [own source]

Based on the evidence supplied from the third parties, the assessor determines the rating of the building and prepares a report containing the details of the building's performance as measured against the BRE Environmental and Sustainability Standard.

If the assessor has got any remarks, the third parties in charge of supplying the evidence should make all the corrections needed and submit the evidence to the assessor for repeated check. Then the assessor prepares the report which contains Executive Summary, BREEAM Certificate Information, Project Team and Building Details, Summary of Building's Assessment Performance, Detailed Assessment of Building Performance and Appendices. Once the registered assessment is completed and verified, it is submitted to BRE Global for the Quality Assurance (QA) and a certification decision. The records can be submitted on paper or in electronic form via BREEAM online system or file transfer 
protocol. All should be submitted in coherent, structured format. Figure 4 shows Final steps of the BREEM assessment algorithm.

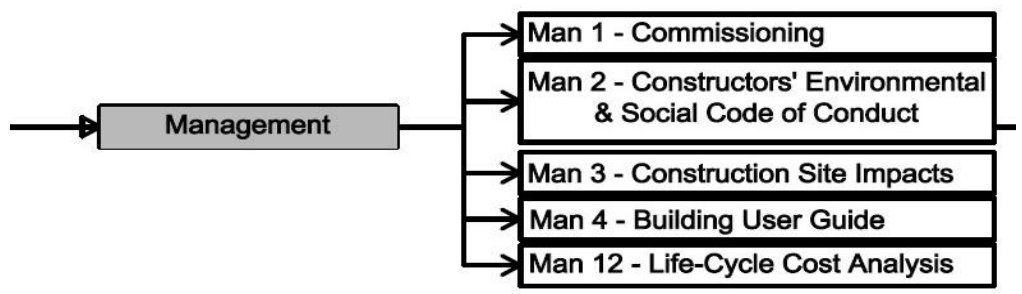

Fig. 3. Crucial part of the BREEAM assessment algorithm - Management elements example [own source]

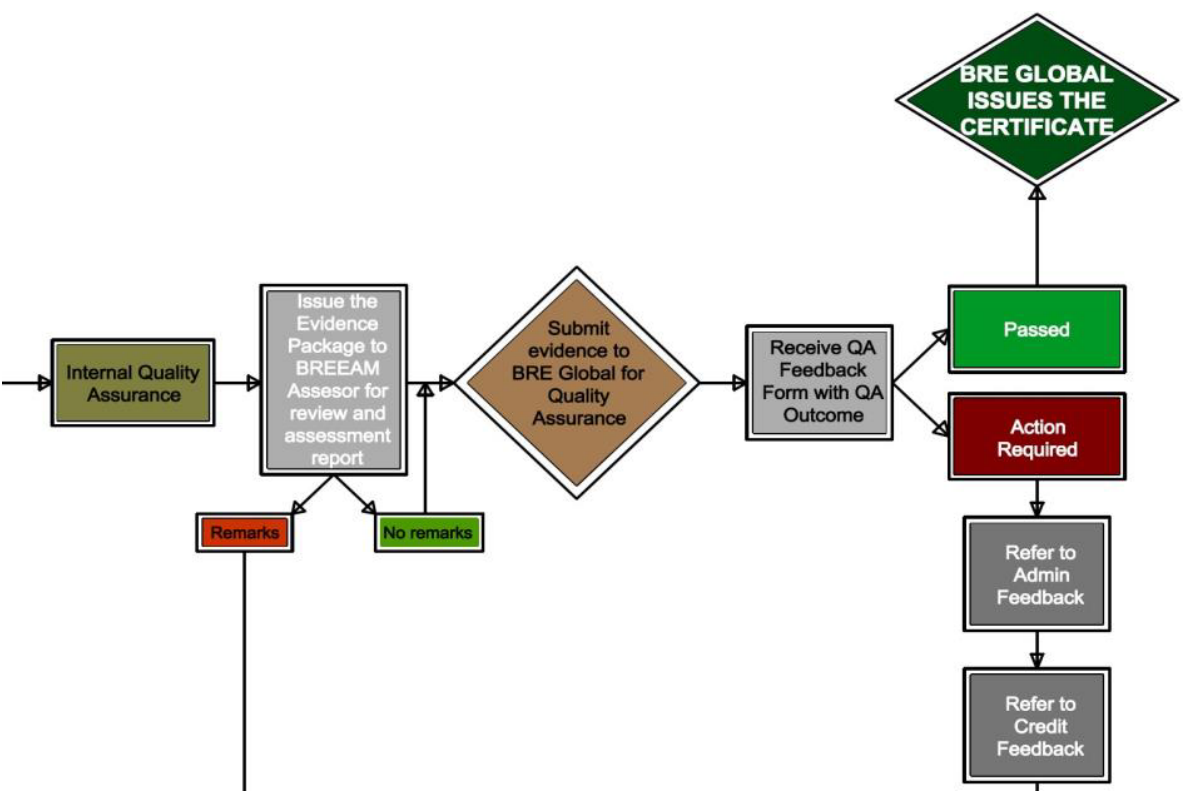

Fig. 4. Final steps of the BREEAM assessment algorithm [own source]

The Quality Assurance process is based on a 'risk-based' approach.

Within the QA analysis, only random criteria are checked, considering the key risk factors likely to affect the quality of the certification, to make sure that the assessor has produced an assessment and rating in accordance with the procedures and processes defined within the Technical Manual. Depending on the scheme type, three or four QA audit levels are distinguished and can be assigned to an assessor after submission an assessment for the certification:

- Administrative audits (carried out on all assessment reports),

- Credit check audit (carried out on a selection of assessments determined by the audit status of a licensed assessor submitting the assessment),

- Partial audits (carried out on a selection of assessments determined by the audit status of a licensed assessor submitting the assessment),

- Full audits (carried out on a selection of assessments determined by the audit status of a licensed assessor submitting the assessment). 
However, when the licensed assessors submit their first assessment, it is subjected to a full audit.

\section{Summary}

After submission of the assessment, BRE Global informs the assessor about the latest date of receiving the QA feedback (depending on the type of audit chosen for the project) and about the possible re-submission required as well. After specific time, Quality Assurance feedback is received. Number of issues, criteria and supporting evidence have been already checked. In case any lack or incorrectness is stated, a non-conformance is identified - depending on how severe it is, it can be classified as either a minor or major non-conformance. As a result, QA audit is not passed. According to BREEAM Operations Manual, a non conformance is typically issued where there is:

- An error/omission resulting in incorrect/invalid assessment,

- No or incorrect documentation/evidence provided,

- Inappropriate/inaccurate referencing of documentation/evidence.

In such a case, appropriate improvements need to be made (as the algorithm shows, one should refer to the feedback and get back to the point of gathering appropriate evidence) and the corrected assessment should be re-submitted for further checks. To prevent from common errors, BRE Global has prepared the list of standard examples of minor and major non-conformances. Described procedure should be repeated until the assessment passes the appropriate level of Quality Assurance. At this stage, the assessment can be finally certified.

\section{References}

1. Building Research Establishment Global materials, www.breglobal.com, (2016)

2. SD 5066A: Issue 1.1 BREEAM Europe Commercial 2009 Assessor Manual (2012)

3. SD 5070 v5.1. BREEAM Operations Manual (2016)

4. The Green Guide Explained, BRE Global (March 2016)

5. N. Ibadov, J. Rosłon,. Archives of Civil Engineering, 61(3), 105-118 (2015)

6. M. Krzemiński, M. Książek, Warsztaty Inżynierów Budownictwa,,Problemy przygotowania i realizacji inwestycji budowlanych”, 249-254 (Puławy 2008),

7. M. Książek, P. Nowak, J. Rosłon, T. Wieczorek, Procedia Engineering, 91, 406-411 (2014)

8. M.V. Książek, P.O. Nowak, S. Kivrak, J.H. Rosłon, L. Ustinovichius, Journal of civil engineering and management, 21(2), 248-259 (2015)

9. M. Książek, P. Nowak, Logistyka, 6 (2009)

10. L. Ustinovichius, E. Zavadskas, D. Migilinskas, A. Malewska, P. Nowak, A. Minasowicz, (2006, September). In International Conference on Cooperative Design, Visualization and Engineering, 295-302 (Springer Berlin Heidelberg, 2006),

11. M. Kaftanowicz, M. Krzemiński, Procedia Engineering, 111, 364-370 (2015)

12. B. Jankowski, J. Prokocki, M. Krzemiński, Procedia Engineering 111, 351-355 (2015)

13. E. Radziszewska-Zielina, ACE 62(2), 167 (2016)

14. E. Radziszewska-Zielina, G. Śladowski, Journal of Cultural Heritage (2017) 